\title{
Playing Digital Game Motivations of University Students
}

\author{
Murat Turgut ${ }^{1}$ \\ Onur Mutlu Yasar ${ }^{2}$ (D)
}

12Kastamonu University, School of Physical Education and Sports, Kastamonu, Turkey. 'Email: mturgut@kastamonu.edu.tr Tel:05466517898

Email: onurmutluyasar@kastamonu.edu.tr Tel: 05327411949

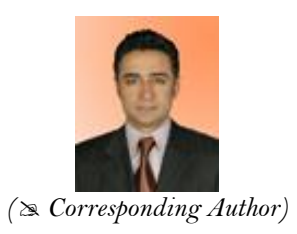

\begin{abstract}
Digital gaming involves all kinds of activities, both individually and as a team, in an online or offline environment through an electronic device. It is stated that the age of playing digital games has decreased to 5-6 years. The aim of this study is to investigate the motivation of students in different faculties of Kastamonu University to play digital games according to gender, age, faculty, class, income and frequency of playing. The research is a descriptive research conducted with quantitative research method. A total of 400 students participated from Kastamonu University in Turkey. In the research, digital game playing motivation scale developed by Munusturlar and Munusturlar (2018) was used as a measurement tool. In the study, the normal distribution of the data was determined by kurtosis and skewness values, and parametric analysis methods One-Way Anova and Independent $\mathrm{T}$ test were used. The motivation of the participants to play digital games was determined at medium and high levels. According to the results, differences were found according to the variables of gender, department, age, class and income status. According to a study of men playing digital games motivation levels are higher than women. In addition, participants with better financial status are more motivated to play digital games. In addition, older participants have higher motivation to play digital games.
\end{abstract}

Keywords: Digital games, Motivations, Students, University.

Citation | Murat Turgut; Onur Mutlu Yasar (2019). Playing Digital Game Motivations of University Students. Asian Journal of Education and Training, 5(4): 603-608.

History:

Received: 19 September 2019

Revised: 22 October 2019

Accepted: 27 November 2019

Published: 23 December 2019

Licensed: This work is licensed under a Creative Commons

Attribution 3.0 License $(\mathrm{oc})$ )

Publisher: Asian Online Journal Publishing Group
Acknowledgement: Both authors contributed to the conception and design of the study.

Funding: This study received no specific financial support

Competing Interests: The authors declare that they have no conflict of interests.

Transparency: The authors confirm that the manuscript is an honest, accurate, and transparent account of the study was reported; that no vital features of the study have been omitted; and that any discrepancies from the study as planned have been explained.

Ethical: This study follows all ethical practices during writing.

\section{Contents}

1. Introduction

2. Material and Method.

References. 


\section{Contribution of this paper to the literature}

This study contributes to the literature in terms of digital gaming habits of university students as digital gaming has spread around the world and many tournaments are organized and even many leading football teams have e-sport teams. Thus, a need for revealing attitude of university students towards digital gaming is important.

\section{Introduction}

The concept of play is considered as a phenomenon that exists with human history. In the literature, the concept of game is evaluated in two parts as traditional and digital games. While the games evaluated within the traditional game concept have more physical activity and movement, it is seen that the games within the concept of digital game contain less physical activity and more mental activity (Hazar and Hazar, 2017) Traditional games have more physical activity and movement, and digital games have less physical activity and more mental activity.

Digital gaming involves all kinds of activities, both individually and as a team, in an online or offline environment through an electronic device (Esposito, 2005). In other words, the concept of digital game is expressed as games that provide animated graphics and sound effects, as well as immersive simulation (Liu and Chen, 2013). It is seen that the history of digital game research has emerged since the 1980s (Bryce and Rutter, 2006). It is stated that 1 billion people in the world play digital games. In addition, it is stated that the age of playing digital games has decreased to 5-6 years.

It can be stated that this situation develops as a result of increasing use and frequency of smart phones, tablets and computers entering human life (Yücel, 2019). Action games, adventure games, simulation games, sports games, strategic games, puzzle games and role playing games are some of the digital games (Gros, 2007). A lot of research has been done recently on digital games (Cota and Ishitani, 2015; De Schutter et al., 2015; Denisova and Cairns, 2015; Bopp et al., 2016; De Grove et al., 2016; Mattar and Goi, 2019).

In the USA, it is stated that $97 \%$ of children and young people devote time to digital games for at least one hour per day (Granic et al., 2014). Our country is among countries where digital games are played the most, Turkey is the third country in the world where digital gaming is played so widely. A total of 30 million people in Turkey play digital games and it is stated that this sector counts for 600 million dollars ${ }^{15}$. In this context, the concept of digital game that has an important place in Turkey's interest for this concept is expected to be further developed. The popularity of digital games today allows young people to spend their time playing online or offline digital games rather than outdoor activities (Eskasasnanda, 2017).

In this context, it is generally accepted that there are positive and negative aspects of digital games. The lack of physical activity and the reduction of face-to-face social relationships among digital games can be given as an example of the negative aspects of playing digital games (Mustafaoğlu et al., 2018). In addition, online games of digital games create a different social environment. It is stated that digital games, which can also be used within educational administrations, have positive effects on individuals' mental behaviours such as decision making, focusing and quick thinking.

The aim of this study is to investigate the motivation of students who study in different faculties in Kastamonu University according to gender, age, faculty, class, income status.

\section{Material and Method}

The research was conducted using quantitative research methods. The study group consists of 400 students, (162 women and 238 men) studying at Kastamonu University in Turkey. In the research, digital game playing motivation scale developed by Munusturlar and Munusturlar (2018) which was composed of 17 questions and 5 sub-dimensions, was used as a measurement tool Munusturlar and Munusturlar (2018). Written and oral consent forms were obtained from each participant in the research and the research was conducted according to the declaration of Helsinki.

The Kurtosis and skewness values of the data obtained within the scope of the study were examined and it was found that the data showed normal distribution (Can, 2016). In this context, One Way Anova was used for groups with more than two variables, and $\mathrm{T}$ test analyses were used for groups with more than two variables. Also data coronach alpha value was determined of 90. level. Table 1 shows demographic information of participants.

Table-1. Demographic information of participants

\begin{tabular}{l|l|c|c}
\hline \multicolumn{2}{|c|}{} & $\mathbf{n}$ & $\mathbf{\%}$ \\
\hline \multirow{3}{*}{ Gender/sex } & Man & 162 & 40.5 \\
\cline { 2 - 4 } & Woman & 238 & 59.5 \\
\hline \multirow{4}{*}{ Age } & $18-21$ & 157 & 39.3 \\
\cline { 2 - 4 } & $22-25$ & 229 & 57.3 \\
\cline { 2 - 4 } & 25 and above & 14 & 3.4 \\
\hline \multirow{4}{*}{ Faculty/School } & Faculty of Architecture and Engineering & 100 & 25 \\
\cline { 2 - 4 } & Faculty of Economics and Administrative Sciences & 100 & 25 \\
\cline { 2 - 4 } & Faculty of Sports & 100 & 25 \\
\cline { 2 - 4 } & Faculty of Arts and Science & 100 & 25 \\
\hline \multirow{4}{*}{ Grade/Class } & 1 & 62 & 15.5 \\
\cline { 2 - 4 } & 2 & 70 & 17.5 \\
\cline { 2 - 4 } & 3 & 127 & 31.7 \\
\cline { 2 - 4 } & 4 & 141 & 35.3 \\
\hline \multirow{2}{*}{$\begin{array}{l}\text { Income } \\
\text { (Monthly) }\end{array}$} & O-500 TL & 115 & 28.7 \\
\cline { 2 - 4 } & $501-1500$ TL & 173 & 43.3 \\
\cline { 2 - 4 } & 1500 TL and above & 112 & 28 \\
\hline Total & & 400 \\
\hline
\end{tabular}


Information related to age, educational status, grade, income of the participants can be found in Table 1. 162 men and 238 women participated in this study which counts for $40,5 \%$ for men and 59,5 for women. The most of the participants were from the age group of 22-25. Distribution of the students in terms of their faculties were equal. Income status of the students did not significantly change and most students had an income level of 501-1500 TL.

\section{Findings}

The data on the digital game motivation scale sub-dimensions and the averages and kurtosis and skewness values of the participants are given in Table 2.

\begin{tabular}{|c|c|c|c|}
\hline Sub-dimensions & $\mathbf{X}^{-}$ & Skewness & Kurtosis \\
\hline Concentration & 2.75 & .380 & .363 \\
\hline Entertainment & 3.40 & -.496 & -.589 \\
\hline Escape & 2.85 & -.073 & -.899 \\
\hline Learning & 2.80 & .007 & -.938 \\
\hline Socializing & 3.10 & -.311 & -.780 \\
\hline Total & 2.97 & -.298 & -.394 \\
\hline
\end{tabular}

Accordingly data analyses, the sub-dimension with the highest average was found to be the entertainment subdimension and the sub-dimension with the lowest average was the concentration sub-dimension. In addition, the total score obtained from the digital game motivation scale was 2.97 .

Table-3. T-test results of participants according to gender variable.

\begin{tabular}{|c|c|c|c|c|c|c|}
\hline Sub-dimensions & Gender/Sex & $\mathbf{n}$ & $\mathbf{X}^{-}$ & Ss & $\mathbf{p}$ & Difference \\
\hline \multirow{2}{*}{ Concentration } & $\operatorname{Man}(1)$ & 162 & 2.52 & 1.11 & \multirow[t]{2}{*}{.001} & \multirow{2}{*}{$1>2$} \\
\hline & Woman (2) & 238 & 2.91 & 1.12 & & \\
\hline \multirow{2}{*}{ Entertainment } & Man (1) & 162 & 3.04 & 1.14 & \multirow[t]{2}{*}{.000} & \multirow{2}{*}{-} \\
\hline & Woman (2) & 238 & 3.65 & 1.09 & & \\
\hline \multirow{2}{*}{ Escape } & $\operatorname{Man}(1)$ & 162 & 2.47 & 1.09 & \multirow[t]{2}{*}{.000} & \multirow{2}{*}{$1>2$} \\
\hline & Woman (2) & 238 & 3.11 & 1.08 & & \\
\hline \multirow{2}{*}{ Learning } & $\operatorname{Man}(1)$ & 162 & 2.36 & 1.03 & \multirow{2}{*}{.000} & \multirow{2}{*}{$1>2$} \\
\hline & Woman (2) & 238 & 3.10 & 1.07 & & \\
\hline \multirow{2}{*}{ Socializing } & $\operatorname{Man}(1)$ & 162 & 2.68 & 1.18 & \multirow{2}{*}{.000} & \multirow{2}{*}{$1>2$} \\
\hline & Woman (2) & 238 & 3.38 & 1.08 & & \\
\hline \multirow{2}{*}{ Total } & $\operatorname{Man}(1)$ & 162 & 2.61 & 0.87 & \multirow{2}{*}{.000} & \multirow{2}{*}{$1>2$} \\
\hline & Woman (2) & 238 & 3.22 & 0.83 & & \\
\hline
\end{tabular}

Table 3 shows t-test results according to gender variables of participants. According to the gender variable, the mean scores of male participants were found to be higher than the female participants in the total score and concentration, escape, learning, and socialization sub-dimensions. In other words, male participants' motivation to play digital games was higher than female participants.

Table-4. Results of anova by age variable.

\begin{tabular}{|c|c|c|c|c|c|c|}
\hline Sub-dimensions & Age & $\mathbf{n}$ & $\mathbf{X}^{-}$ & Ss & $\mathbf{p}$ & Difference \\
\hline \multirow{3}{*}{ Concentration } & $18-21(1)$ & 157 & 2.62 & 1.07 & \multirow{3}{*}{.078} & \multirow{3}{*}{ - } \\
\hline & $22-24(2)$ & 229 & 2.82 & 1.15 & & \\
\hline & 25 and above $(3)$ & 14 & 3.19 & 1.31 & & \\
\hline \multirow{3}{*}{ Entertainment } & $18-21(1)$ & 157 & 3.32 & 1.17 & \multirow{3}{*}{.113} & \multirow{3}{*}{-} \\
\hline & $22-24(2)$ & 229 & 3.43 & 1.14 & & \\
\hline & 25 and above $(3)$ & 14 & 3.98 & 1.03 & & \\
\hline \multirow{3}{*}{ Escape } & $18-21(1)$ & 157 & 2.69 & 1.13 & \multirow{3}{*}{.030} & \multirow{3}{*}{$\begin{array}{c}3>1,2 \\
2>1\end{array}$} \\
\hline & $22-24(2)$ & 229 & 2.93 & 1.11 & & \\
\hline & 25 and above (3) & 14 & 3.35 & 1.19 & & \\
\hline \multirow{3}{*}{ Learning } & $18-21(1)$ & 157 & 2.66 & 1.12 & \multirow{3}{*}{.091} & \multirow{3}{*}{ - } \\
\hline & $22-24(2)$ & 229 & 2.89 & 1.10 & & \\
\hline & 25 and above $(3)$ & 14 & 3.07 & 1.14 & & \\
\hline \multirow{3}{*}{ Socializing } & $18-21(1)$ & 157 & 2.97 & 1.19 & \multirow{3}{*}{.198} & \multirow{3}{*}{-} \\
\hline & $22-24(2)$ & 229 & 3.18 & 1.14 & & \\
\hline & 25 and above $(3)$ & 14 & 3.21 & 1.22 & & \\
\hline \multirow{3}{*}{ Total } & $18-21(1)$ & 157 & 2.85 & 0.86 & \multirow{3}{*}{.027} & \multirow{3}{*}{$3,2>1$} \\
\hline & $22-24(2)$ & 229 & 3.04 & 0.90 & & \\
\hline & 25 and above (3) & 14 & 3.38 & 1.02 & & \\
\hline
\end{tabular}

Table 4 shows anova results according to age variables of participants. According to the age variable, the mean scores of the group above 25 years of age in the escape subscale and total score were higher than the other groups. In addition, the mean scores of the 21-24 age group in the escape subscale were found to be higher than the mean scores of the 18-21 group. In the total score, the mean scores of the group above 25 years of age were higher than the other groups. According to these results, it is seen that the motivation to play digital games increases with increasing age. 
Table-5. Anova results of the participants according to faculty variables.

\begin{tabular}{|c|c|c|c|c|c|c|}
\hline Sub-dimensions & Faculty/School & $\mathbf{n}$ & $\mathbf{X}^{-}$ & Ss & p & Difference \\
\hline \multirow{4}{*}{ Concentration } & Faculty of Architecture and Engineering (1) & 102 & 2.75 & 1.04 & \multirow{4}{*}{.013} & \multirow{4}{*}{$2>4$} \\
\hline & $\begin{array}{llll}\text { Faculty of Economics and Administrative } \\
\text { Sciences }(2)\end{array}$ & 99 & 3.01 & 1.04 & & \\
\hline & Faculty of Sports (3) & 99 & 2.76 & 1.24 & & \\
\hline & Faculty of Arts and Science (4) & 100 & 2.49 & 1.14 & & \\
\hline \multirow{4}{*}{ Entertainment } & Faculty of Architecture and Engineering (1) & 102 & 3.35 & 1.06 & \multirow{4}{*}{.421} & \multirow{4}{*}{-} \\
\hline & $\begin{array}{l}\text { Faculty of Economics and Administrative } \\
\text { Sciences (2) }\end{array}$ & 99 & 3.51 & 1.07 & & \\
\hline & Faculty of Sports (3) & 99 & 3.48 & 1.36 & & \\
\hline & Faculty of Arts and Science (4) & 100 & 3.27 & 1.10 & & \\
\hline \multirow{4}{*}{ Escape } & Faculty of Architecture and Engineering (1) & 102 & 3.01 & 1.07 & \multirow{4}{*}{.003} & \multirow{4}{*}{$1,2,3>4$} \\
\hline & $\begin{array}{llll}\text { Faculty of Economics and Administrative } \\
\text { Sciences }(2)\end{array}$ & 99 & 2.96 & 1.08 & & \\
\hline & Faculty of Sports (3) & 99 & 2.92 & 1.24 & & \\
\hline & Faculty of Arts and Science (4) & 100 & 2.49 & 1.05 & & \\
\hline \multirow{4}{*}{ Learning } & Faculty of Architecture and Engineering (1) & 102 & 3.21 & 1.00 & \multirow{4}{*}{.000} & \multirow{4}{*}{$\begin{array}{l}1>2,3,4 \\
2,3>4\end{array}$} \\
\hline & $\begin{array}{llll}\text { Faculty of Economics and Administrative } \\
\text { Sciences }(2)\end{array}$ & 99 & 2.90 & 1.05 & & \\
\hline & Faculty of Sports (3) & 99 & 2.77 & 1.18 & & \\
\hline & Faculty of Arts and Science (4) & 100 & 2.34 & 1.05 & & \\
\hline \multirow{4}{*}{ Socializing } & Faculty of Architecture and Engineering (1) & 102 & 3.22 & 1.10 & \multirow{4}{*}{.579} & \multirow{4}{*}{-} \\
\hline & $\begin{array}{l}\text { Faculty of Economics and Administrative } \\
\text { Sciences (2) }\end{array}$ & 99 & 3.11 & 1.09 & & \\
\hline & Faculty of Sports $(3)$ & 99 & 3.08 & 1.28 & & \\
\hline & Faculty of Arts and Science (4) & 100 & 2.99 & 1.20 & & \\
\hline \multirow{4}{*}{ Total } & Faculty of Architecture and Engineering (1) & 102 & 3.10 & 0.84 & \multirow{4}{*}{.003} & \multirow{4}{*}{$1.2 .3>4$} \\
\hline & $\begin{array}{llll}\text { Faculty of Economics and Administrative } \\
\text { Sciences }(2)\end{array}$ & 99 & 3.11 & 0.83 & & \\
\hline & Faculty of Sports $(3)$ & 99 & 3.00 & 1.06 & & \\
\hline & Faculty of Arts and Science (4) & 100 & 2.69 & 0.77 & & \\
\hline
\end{tabular}

Table 5 shows anova results according to faculty variables of participants. According to the faculty/School variable, the participants who have the highest motivation to play digital games are the students of the Faculty of Economics and Administrative Sciences, Faculty of Architecture and Engineering, Faculty of Sports and Faculty of Arts and Science respectively.

Table-6. Anova results according to class variables.

\begin{tabular}{|c|c|c|c|c|c|c|}
\hline Sub-dimensions & Grade/Class & $\mathbf{n}$ & $\mathrm{X}^{-}$ & Ss & p & Difference \\
\hline \multirow{4}{*}{ Concentration } & 1 & 62 & 2.64 & 1.01 & \multirow{4}{*}{.634} & \multirow{4}{*}{-} \\
\hline & 2 & 127 & 2.72 & 0.89 & & \\
\hline & 3 & 70 & 2.72 & 1.11 & & \\
\hline & 4 & 141 & 2.84 & 1.29 & & \\
\hline \multirow{4}{*}{ Entertainment } & 1 & 62 & 3.37 & 1.24 & \multirow{4}{*}{.792} & \multirow{4}{*}{-} \\
\hline & 2 & 127 & 3.33 & 0.99 & & \\
\hline & 3 & 70 & 3.38 & 1.15 & & \\
\hline & 4 & 141 & 3.48 & 1.19 & & \\
\hline \multirow{4}{*}{ Escape } & 1 & 62 & 2.78 & 1.13 & \multirow{4}{*}{.275} & \multirow{4}{*}{-} \\
\hline & 2 & 127 & 2.66 & 1.05 & & \\
\hline & 3 & 70 & 2.85 & 1.14 & & \\
\hline & 4 & 141 & 2.97 & 1.15 & & \\
\hline \multirow{4}{*}{ Learning } & 1 & 62 & 2.81 & 1.07 & \multirow{4}{*}{.031} & \multirow{4}{*}{$3,4>2$} \\
\hline & 2 & 127 & 2.45 & 0.99 & & \\
\hline & 3 & 70 & 2.92 & 1.11 & & \\
\hline & 4 & 141 & 2.87 & 1.17 & & \\
\hline \multirow{4}{*}{ Socializing } & 1 & 62 & 3.04 & 1.25 & \multirow{4}{*}{.226} & \multirow{4}{*}{-} \\
\hline & 2 & 127 & 2.86 & 1.16 & & \\
\hline & 3 & 70 & 3.14 & 1.08 & & \\
\hline & 4 & 141 & 3.20 & 1.20 & & \\
\hline \multirow{4}{*}{ Total } & 1 & 62 & 2.92 & 0.77 & \multirow{4}{*}{.249} & \multirow{4}{*}{-} \\
\hline & 2 & 127 & 2.81 & 0.77 & & \\
\hline & 3 & 70 & 2.99 & 0.91 & & \\
\hline & 4 & 141 & 3.06 & 0.97 & & \\
\hline
\end{tabular}

Table 6 shows anova results according to class variables of participants. There was a statistically significant difference only in learning sub-dimension according to class variable. According to the results, the average of the 3rd and 4th grade points were found to be higher than the 2nd grade group average scores. In other words, it is seen that with the increase in the class levels of the participant students, the status of seeing digital games as a learning activity increases. 
Table-7. Anova results according to income variables.

\begin{tabular}{|c|c|c|c|c|c|c|}
\hline Sub-dimensions & Income (Monthly) & $\mathbf{n}$ & $\mathrm{X}^{-}$ & Ss & p & Difference \\
\hline \multirow{3}{*}{ Concentration } & $0-500 \mathrm{TL}(1)$ & 115 & 2.76 & 1.27 & \multirow{3}{*}{.718} & \multirow{3}{*}{-} \\
\hline & $501-1500$ TL $(2)$ & 173 & 2.70 & 1.02 & & \\
\hline & $1500 \mathrm{TL}$ and above (3) & 112 & 2.82 & 1.14 & & \\
\hline \multirow{3}{*}{ Entertainment } & $0-500$ TL $(1)$ & 115 & 3.37 & 1.16 & \multirow{3}{*}{.008} & \multirow{3}{*}{$\begin{array}{c}3,1>2 \\
3>1\end{array}$} \\
\hline & $501-1500 \mathrm{TL}(2)$ & 173 & 3.25 & 1.14 & & \\
\hline & $1500 \mathrm{TL}$ and above (3) & 112 & 3.68 & 1.12 & & \\
\hline \multirow{3}{*}{ Escape } & $0-500$ TL $(1)$ & 115 & 2.73 & 1.10 & \multirow{3}{*}{.001} & \multirow{3}{*}{$3>1,2$} \\
\hline & $501-1500$ TL $(2)$ & 173 & 2.70 & 1.10 & & \\
\hline & 1500 TL and above (3) & 112 & 3.20 & 1.13 & & \\
\hline \multirow{3}{*}{ Learning } & O-500 TL (1) & 115 & 2.59 & 1.09 & \multirow{3}{*}{.001} & \multirow{3}{*}{$3>1,2$} \\
\hline & $501-1500$ TL $(2)$ & 173 & 2.74 & 1.09 & & \\
\hline & 1500 TL and above (3) & 112 & 3.12 & 1.11 & & \\
\hline \multirow{3}{*}{ Socializing } & O-500 TL (1) & 115 & 3.00 & 1.23 & \multirow{3}{*}{.074} & \multirow{3}{*}{-} \\
\hline & $501-1500$ TL $(2)$ & 173 & 3.02 & 1.10 & & \\
\hline & 1500 TL and above (3) & 112 & 3.31 & 1.19 & & \\
\hline \multirow{3}{*}{ Total } & O-500 TL (1) & 115 & 2.89 & 0.86 & \multirow{3}{*}{.003} & \multirow{3}{*}{$3>1,2$} \\
\hline & $501-1500$ TL $(2)$ & 173 & 2.88 & 0.87 & & \\
\hline & 1500 TL and above (3) & 112 & 3.22 & 0.92 & & \\
\hline
\end{tabular}

Table 7 shows anova results according to income variables of participants. According to the results of the analysis made according to monthly income variable entertainment, escape and learning sub-dimensions and total score averages. According to the results of the analysis, it is seen that the motivation of playing digital games increases with the increase of monthly income of the participating students.

\section{Discussion and Result}

According to the results of the study conducted by Demirel et al. (2019) to determine the motivation of high school students to play digital games, it was stated that the motivation of female participants to play digital games was lower than that of male participants Demirel et al. (2019). In this context, it is seen that there is a similarity between this research and the study conducted by Demirel et al. (2019) according to gender variable.

Sin et al. (2014) stated that the male students' motivation to play digital games was investigated according to the results of the study, it was stated that the emotions that provide the motivation to play digital games of the male students have the challenge and control emotions (Sin et al., 2014). In this context, the results of this study and the research conducted by Sin et al. In addition, according to the results of the research conducted by Sin et al. (2014) It was stated that the most intense emotion felt by digital game players while playing digital games was entertainment. In this context, there are similarities between the two studies.

As a result of general research, it is stated in many studies that men have higher motivation to play digital games than women. This can be attributed to the fact that men have more leisure time and less sense of responsibility than women.

Birk and Mandryk (2016) stated that digital game athletes' preferences and player experiences were examined according to the age variable (Birk and Mandryk, 2016) According to the results of the study, it was stated that the motivation to play increased with the increasing age of participants. It is seen that there is a similarity between this research and the results of the research conducted by (Birk and Mandryk, 2016).

According to the results of the research conducted by Hazar (2019) on the motivation of playing digital games in children, their interest in digital games increased with increasing age (Hazar, 2019). In this context, it is stated that there is a similarity between the results of the research conducted by Hazar and the results of this study according to the age variable.

An increase in an individual's ability to play can increase motivation to play. In addition, the increase in the number and variety of games that the individual can play with age can be shown as the reason of the result obtained.

Nap et al. (2009) according to the results of qualitative research conducted on the motivation, preferences and needs of digital game athletes, it was stated that the participants answered the question of why they are playing digital games in terms of escape and entertainment (Nap et al., 2009).

In this context, it is seen that there is a similarity between the results of this research and the results of the research conducted by Nap. In today's world, increasing stress levels of people and because of this people need to escape from stress and have fun. In this sense, individuals are expected to see digital games as an escape and entertainment activity. In this sense, it is normal for individuals to consider digital games as an escape and entertainment activity.

According to the results of the research conducted by Cavuş et al. (2016) on computer games and addictions of university students, it was determined that the level of addiction increased as the income level increased Cavuş et al. (2016). In this sense, the results of this research and the research conducted by Cavuş et al. (2016) are similar in terms of income levels.

It can be explained by people's ability to buy games and game consoles as addiction and motivation to play digital games increases as the income level increases.

According to Cakir et al. (2011) research on internet and game addictions of university students, it was determined that there was no significant difference in terms of game addiction to the classes in which the participating students Cakır et al. (2011). There are differences between the results of the research conducted by Cakır et al. (2011) and this research. Cultural differences between the two research participants can be cited as the reason for this result. 
According to the results of the research, it can be stated that the difference in the learning sub-dimension is related to the increase in the level of awareness and effort increase of learning activities. According to the results of the analyses, it is thought that the students who have received sports education generally have low average scores and their participation in physical activities is higher than other faculty students.

As a result of the research results, it was found that the participants 'motivation to play digital games was moderate and high, as well as gender, age, class, income and faculty variables showed differences according to the participants' motivation to play digital games.

\section{References}

Birk, M.V. and R.L. Mandryk, 2016. The benefits of digital games for the assessment and treatment of mental health. In CHI 2016 Workshop Computing in Mental Health.

Bopp, J.A., E.D. Mekler and K. Opwis, 2016. Negative emotion, positive experience?: Emotionally moving moments in digital games. In Proceedings of the 2016 CHI Conference on Human Factors in Computing Systems. pp: 2996-3006.

Bryce, J. and J. Rutter, 2006. An introduction to understanding digital games. London: Sage.

Cakır, Ö., T. Ayas and M.B. Horzum, 2011. An investigation of university students' internet and game addiction with respect to several variables. Ankara University, Journal of Faculty of Educational Sciences, 44(2): 95-117.

Can, A., 2016. Scientific data analysis in SPSS scientific research process. Turkey: Pegem Academy. pp: 186.

Cavuş, S., B. Ayhan and M. Tuncer, 2016. Computer games and addiction: A field study on university students. Journal of Communication Theory and Research, 43(1): 265-289.

Cota, T.T. and L. Ishitani, 2015. Motivation and benefits of digital games for the elderly: A systematic literature review. Brazilian Journal of Applied Computing, 7(1): 2-16.Available at: https://doi.org/10.5335/rbca.2015.4190.

De Grove, F., V. Cauberghe and J. Van Looy, 2016. Development and validation of an instrument for measuring individual motives for playing digital games. Media Psychology, 19(1): 101-125.Available at: https://doi.org/10.1080/15213269.2014.902318.

De Schutter, B., M. Gandy, S. Mosberg Iversen, H. Nap and R. Hunicke, 2015. Digital games in later life: Challenges and opportunities. In Symposium, Foundations of Digital Games.

Demirel, H.G., H.İ. Cicioğlu and G.T. Demir, 2019. Research on the digital game playıng motıvatıon levels of high school students. Atatürk University Journal of Physical Education and Sport Sciences, 21(3): 128-137.

Denisova, A. and P. Cairns, 2015. First person vs. third person perspective in digital games: So player preferences affect immersion? In Proceedings of the 33rd Annual ACM Conference on Human Factors in Computing Systems. pp: 145-148.

Eskasasnanda, I.D.P., 2017. Causes and effects of online video game playing among junior-senior high school students in Malang East Java. Komunitas: International Journal of Indonesian Society and Culture, 9(2): 191-202.Available at: https://doi.org/10.15294/komunitas.v9i2.9565.

Esposito, N., 2005. A short and simple definition of what a videogame is. Available from http:// www.utc.fr/ nesposit/publications/esposito2005definition.pdf.

Granic, I., A. Lobel and R. Engels, 2014. The benefits of playing video games. American Psychologist, 69(1): 66-78.

Gros, B., 2007. Digital games in education: The design of games-based learning environments. Journal of Research on Technology in Education, 40(1): 23-38.Available at: https://doi.org/10.1080/15391523.2007.10782494.

Hazar, Z., 2019. An analysis of the relationship between digital game playing motivation and digital game addiction among children. Asian Journal of Education and Training, 5(1): 31-38.Available at: https://doi.org/10.20448/journal.522.2019.51.31.38.

Hazar, Z. and M. Hazar, 2017. Digital game addiction scale for children. Journal of Human Sciences, 14(1): $203-216$.

Liu, E.Z.F. and P.-K. Chen, 2013. The effect of game-based learning on students' learning performance in science learning-a case of conveyance go. Procedia-Social and Behavioral Sciences, 103: 1044-1051.Available at: https://doi.org/10.1016/j.sbspro.2013.10.430.

Mattar, J. and V.M. Goi, 2019. Digital games for diagnostic assessment of cognitive skills and competences: Literature review and framework. In Handbook of Research on Immersive Digital Games in Educational Environments. IGI Global. pp: $260-286$.

Munusturlar, M.A. and S. Munusturlar, 2018. Development of computer gaming motivation scale. Journal of Spormetre, 16(3): $81-90$.

Mustafaoğlu, R., E. Zirek, Z. Yasacı and A.R. Özdinçler, 2018. Adverse effects of digital technology on children's development and health. Addicta: The Turkish Journal on Addictions, 5(2): 1-21.Available at: https://doi.org/10.15805/addicta.2018.5.2.005 1.

Nap, H., Y. De Kort and W. IJsselsteijn, 2009. Senior gamers: Preferences, motivations and needs. Gerontechnology, 8(4): 247-262.Available at: https://doi.org/10.4017/gt.2009.08.04.003.00.

Sin, N.M., O. Talib, T.P. Norishah, A.A. Ishak and R. Baki, 2014. Male students and digital game: Reason, motivation and feeling. International Journal of Information and Education Technology, 4(1): 6-11.

Yücel, V., 2019. Harmful digital games and children. Eurasian Journal of Researches in Social and Economics (EJRSE), 6(7): 340-353. 